\title{
PARK VERSUS SIMMEL: INDIVÍDUO E SOCIEDADE DO PONTO DE VISTA
}

ECOLÓGICO

Ana Carolina Vila Ramos dos Santos

\section{RESUMO}

Tomo como objetivo, nesse trabalho, perscrutar de que forma a ecologia humana de Robert Park se aproxima do evolucionismo social e das ciências naturais e se afasta do pensamento de Georg Simmel, uma possível raiz desta ecologia humana identificados pela literatura. Pretendo mostrar de que forma a ecologia humana dos americanos se molda ao gabarito das ciências naturais e se afasta da teoria sociológica conformando numa ecologia essencialmente "naturalista", um aporte antípoda às propostas de Simmel.

Palavras-chave: Natureza; Escola de Chicago; Teoria Sociológica

\section{PARK VERSUS SIMMEL: INDIVIDUAL AND SOCIETY FROM A ECOLOGICAL POINT OF VIEW}

\begin{abstract}
This articule assumes as aim to scrutinize how the human ecology of Robert Park is more closer to the social evolucionism and natural sciences approaches than the thought of Georg Simmel, a possible root of human ecology identified in the literature. I intend to show how the human ecology of the Park is molded to natural sciences conforming an essentially "naturalist" approach completely antipodal to Simmel thought.
\end{abstract}

Keywords: Nature; Chicago School; Sociological Theory 


\section{Introdução}

Já na década de 1910, a Universidade de Chicago começa a se destacar como centro produtor de conhecimento no campo das ciências humanas nos EUA. Robert E. Park e Ernest Burgess e um grande grupo ligado à institucionalização e estruturação do departamento de ciências sociais naquela universidade lança as bases de uma grande vertente teórica nas ciências humanas naquele período: a ecologia humana. Como salienta Oliveira (1987), a ecologia humana tem tamanha importância na institucionalização das ciências sociais americanas que até hoje se pode perceber que as proposições da ecologia humana persistem como marca distintiva da sociologia americana.

Nos estudos dessa importante “escola”, são sugeridos inúmeros diálogos; se há um nome sempre lembrado como referência nos estudos da chamada ecologia humana da Escola de Chicago esse é o de George Simmel. Neste trabalho, tomo como objetivo apresentar as distâncias e proximidades entre um dos expoentes da Ecologia Humana da Escola de Chicago, Robert Park, e esse autor clássico do pensamento sociológico, George Simmel. Para olhar para esse diálogo, escolhi um tema pouco tratado na literatura sociológica, mas que permite um acesso original e claro a outros temas clássicos do pensamento sociológico (como a relação entre sociedade e indivíduo da qual nos ocuparemos ao final do trabalho): refiro-me à relação sociedade e natureza. Proponho, então, que a partir das leituras que ambos apresentaram sobre natureza e sociedade em suas obras, é possível perceber as peculiaridades das propostas de cada autor no que diz respeito, principalmente, à relação indivíduo e sociedade.

Como primeiro passo nesse breve estudo, é necessário apresentar algumas informações básicas sobre a chamada Ecologia Humana da Escola de Chicago, tendo como “ideia-guia" nesse empreendimento a relação sociedade e natureza.

Começamos essa longa jornada afirmando que não há, na sociologia norte-americana das primeiras décadas do século XX, uma inconsistência entre aceitar o homem como um ser vivo dentre outros e o homem como único ser vivo que conseguiu dominar e subverter a natureza, isto é, não há divergência em reduzir o homem a seus caracteres biológicos e aceitálo no que o torna peculiar (porque é capaz de transformar e submeter a natureza) em meio aos outros seres vivos. Na argumentação de Robert Park (1948) isso fica bem claro quando ele estuda o mundo social a partir de dois níveis, o biótico e o sociológico. No nível biótico, o homem é um ser vivo entre outros: pensa-se em processos naturais e autônomos da vontade humana. Já no nível sociológico, o homem é tomado em sua peculiaridade e pensa-se em 
processos sociais e totalmente ligados à vontade humana.

Para melhor entender (sem pretender, nem de longe, esgotar a problemática), é possível e desejável identificar quais os diálogos travados entre Robert Park e seus contemporâneos com o pensamento social de fins do século XIX e início do século XX na conformação de suas propostas ecológicas. Nas leituras sobre a ecologia humana de Robert Park, são instáveis as filiações teóricas identificadas pela literatura especializada ${ }^{1}$; alguns nos falam do social darwinismo, sem nos dizer como se dá essa filiação (FARIS, 1967); outros nos falam do pragmatismo, sem explicar ao certo qual o lugar da ecologia nos estudos de John Dewey e William James (FARIS, 1967; PIERSON, 1947;1948 a,b); outros autores nos contam sobre a influência simmeliana na conformação de conceitos centrais da ecologia humana (PARK, 1948; PIERSON, 1947;1948). O que objetivo fazer nesse espaço é esclarecer as propostas de Park via seus diálogos com as inúmeras ideias que "estavam por ali“" quando da elaboração de sua ecologia.

Tal como uma colcha de retalhos, a ecologia humana de Park é costurada a partir de várias matrizes teóricas que enlaçam no mesmo cadinho propostas tão díspares quanto às de Simmel e Spencer. A imagem da colcha de retalhos será mobilizada várias vezes ao longo deste trabalho e é importante esclarecer o que entende-se por essa invocação: a colcha de retalhos é um produto artesanal e único elaborado em um longo período e para o qual dedicase muita atenção e esmero; uma colcha de retalhos congrega em si elementos díspares que, surpreendentemente, quando combinados conformam uma bela harmonia; para além da harmonia, os elementos que compõem a colcha, antes tão diferentes a ponto de serem incombináveis, quando conjugados contam-nos uma história, imprimem um sentido renovado ao conjunto de retalhos que compõem esse novo elemento, a colcha.

A ecologia humana de Robert Park, gostaríamos de propor, é composta por elementos tão distantes quanto o evolucionismo social e a sociologia simmeliana, mas quando combinados, tal como uma colcha de retalhos, assumem uma individualidade, tomam um sentido próprio que conformam a originalidade das propostas teóricas e metodológicas de Robert Park e nos contam muito sobre um período crucial na institucionalização do pensamento sociológico nos EUA. Apontaremos, nesse artigo, os elementos que compõem suas ideias em suas proximidades e distâncias, mas é importante esclarecer que, em

\footnotetext{
${ }^{1}$ Alain COULON (1995), Carl N. DEGLER (1991), Robert FARIS (1967) como exemplos na literatura internacional e como referências na literatura nacional temos Donald PIERSON (1947 e 1948 a,b) e Mario A EUFRÁSIO (1999).
}

INTRATEXTOS, Rio de Janeiro, 4(1): 220-239, 2012.

Página 222 
contraposição aos apontamentos da literatura citada nas primeiras páginas desse trabalho, são as distâncias entre as ideias de Park e de Simmel que aqui exploraremos, e não o contrário. Trata-se de uma escolha teórica que pode ser explicada pelos estudos que venho desenvolvendo acerca das distâncias entre a ecologia presente nos "estudos de comunidade" empreendidos no Brasil em meados da década de 1940 (estudos que tem a Ecologia Humana como referência) e a sociologia de Antonio Candido tal como apresentada em "Os Parceiros do Rio Bonito". Sem sombra de dúvidas, há encontros entre essas duas propostas teóricas, contudo acredito que as distâncias, e não as proximidades, nos contam muito mais sobre os rumos da sociologia paulista em seu advento.

Já começo por aventar como hipótese que se poderia pensar na predominância de uma certa lente na costura dessas propostas teóricas e metodológicas na formação da grande colcha da ecologia humana de Park. Essa lente é conformada pelas propostas encampadas pelo o que a literatura chama de evolucionismo social de fins do século XIX. O que quero dizer é que as fronteiras entre as ciências naturais e sociais naquele período eram tão frágeis que não havia contradição alguma em pensar sociologicamente do ponto de vista das ciências naturais. É o esforço pela generalização que preside a predominância da lente das ciências naturais na conformação dessa grande colcha chamada de ecologia humana no pensamento de Robert Park. Assim, como argumentarei ao longo do trabalho, temos que, a despeito da presença de ideias simmelianas "de origem" (como o estrangeiro ou a distância social), não há uma orientação tipicamente simmeliana da ecologia humana, ou seja, a ecologia humana de Park é essencialmente biológica a despeito do "contrabando" sociológico. Aqui fazemos uso de outra imagem que, embora eivada de um conteúdo moral negativo, pode ser de grande utilidade para compreensão do lugar que a sociologia ocupa na conformação da ecologia de Robert E. Park. Contrabando, neste trabalho, é aquilo que é transportado sub-repticiamente, é o elemento clandestino que dilui-se em outros elementos e que oferece um "tempero", uma cor à colcha de retalhos a que nos referimos acima, mas que não constitui elemento central ou estruturante da ecologia de Robert Park. A sociologia em seu conteúdo humanista aparece como elemento clandestino que, embora presente na conformação da colcha de retalhos da ecologia humana de Park, cede grande espaço à episteme das ciências naturais, essa considerada como o gabarito do fazer ciência nas primeiras décadas do século XX nos EUA. Entendamos tais propostas nas seções que seguem.

\section{Darwinismo social}

Um primeiro retalho nessa grande colcha é o darwinismo. Comecemos por Charles 
Darwin e seu desenvolvimento mais importante para a história do pensamento social, o darwinismo social. Vejamos de que modo o darwinismo social se apresenta àqueles que pensaram sociedade em fins do século XIX e início do século XX no mundo ocidental.

O social darwinismo tal como se apresentou nas últimas décadas do século XIX e nas primeiras do século XX nos EUA, tem muito pouco de Darwin e muito mais de Herbert Spencer. Conheçamos primeiro, então, o coração da teoria darwinista para depois tratarmos do social darwinismo.

Na história do pensamento ocidental, desde o período medieval, pode-se dizer que há um predomínio da ideia que toma natureza e sociedade como reinos completamente distintos dotados de uma lógica própria; podemos dizer que há mesmo a defesa da singularidade (e, portanto, superioridade) humana diante de outras criaturas da natureza. O homem está no centro do mundo, sob esta ótica.

O Antropocentrismo dos séculos XIV, XV e XVI coloca a natureza como totalmente subjugada aos desígnios da humanidade. Renée Descartes (1596-1650) e Francis Bacon (1561-1626) trazem esses imperativos de forma clara e inconteste; para Bacon, o fim da ciência era devolver ao homem o domínio sobre a criação que ele perdera em parte com o pecado original. Para os cientistas formados nessa tradição, todo o propósito de estudar o mundo natural se resumia na seguinte proposição: a Natureza, desde que conhecida, será dominada, gerida e utilizada a serviço da vida humana. Nesse sentido, os animais e plantas eram do maior interesse não só por sua diversidade e beleza, mas acima de tudo por sua preeminente utilidade para o gênero humano. O mundo fora criado para o bem do homem e as outras espécies deviam se subordinar a seus desejos e necessidades- essa era a consequência máxima do propósito acima lembrado.

O louvor ao domínio da natureza pelo homem era acompanhado pelo elogio à singularidade humana. Descartes, em meados do século XVII, elabora a formulação clássica a respeito do tema: para o francês, os animais são autômatos capazes de produzir alguns comportamentos complexos, mas incapazes de perfazer comportamentos tipicamente humanos como falar, raciocinar, ou segundo algumas interpretações, até mesmo de ter sensações. Para Descartes, o corpo humano também é um autômato, mas a diferença está em que no seio da máquina humana há a mente e, portanto, uma alma separada, enquanto os seres brutos são autômatos desprovidos de almas ou mentes; para sintetizar, é possível dizer que a superioridade do humano é a combinação simultânea de matéria e intelecto.

O propósito explícito de Descartes fora fazer dos homens senhores e possuidores 
incontestáveis da natureza. Adequava-se bem a sua intenção de tomar os outros seres vivos como inertes e desprovidos de toda dimensão espiritual e, ao fazê-lo, estabeleceu um corte definitivo entre o homem e o restante da natureza, deixando, desta forma, o terreno livre para o exercício ilimitado da dominação humana.

Entretanto, os discursos acerca da superioridade humana frente à natureza e, portanto, o caráter justo da dominação de um pelo outro não reinam soberanos no pensamento ocidental: pode-se sugerir que há uma disputa clara pelo sentido de natureza e humanidade. Essa disputa ganha corpo no século XVI à época dos descobrimentos; o Novo Mundo, sua natureza e sua gente, colocava em xeque o discurso condenatório da natureza e, em fins do século XVI, natureza recebe um sentido renovado- a natureza passa a ser vista como possibilidade de restabelecimento da pureza e da ordem outrora reinantes na humanidade.

É em fins do século XVII que o antropocentrismo passa a ser colocado em questão quando, de um lado, a ciência moderna toma a natureza a partir de critérios mais objetivos e imparciais, e de outro quando o romantismo toma a natureza como depósito infindável de renovação da humanidade. O que é preciso deixar claro é que não há uma soma zero nessa "disputa"- trata-se, antes, da convivência de ideias que ao negarem-se, forjam-se a si mesmas.

Quando Charles Darwin (1809-1882) escreveu sua grande obra "A Origem das Espécies“ (1859), era nessa disputa que o trabalho do autor se inseria e é de uma forma contundente que o estudioso adiciona elementos decisivos a esse debate ao tomar homem e natureza como submetidos aos mesmos processos biológicos de evolução de espécies- em síntese, é possível sugerir que, do ponto de vista de Charles Darwin, espécies tão díspares quanto à tartaruga e a coruja estão submetidas aos mesmos processos evolutivos. Entendamos o significado e impacto dessa proposta.

Darwin dedicou-se a explicar o processo evolutivo, isto é, como animais e plantas tomaram suas formas atuais. Seu argumento central era o princípio da seleção natural; a enorme variedade de seres vivos, argumenta Darwin, é resultado da interação de três mecanismos sintetizados como segue:

- Todos os organismos se reproduzem;

- Todos os organismos, mesmo dentro de uma mesma espécie, são diferentes entre si;

- Os organismos competem entre si pela sobrevivência.

Modificações no ambiente ou a presença de novos organismos no ambiente são as condições determinantes no processo de adaptação das espécies; como resultado desse processo, os organismos melhores adaptados iriam gradualmente se sobrepor àqueles menos 
adaptados. Esse mecanismo de ação foi chamado de seleção natural, pois era a mão da Natureza o artífice desse processo, isto é, a natureza em toda sua força era a forma estruturante das diferentes espécies.

É interessante notar que não há em "A Origens das Espécies”, obra na qual Darwin explana de forma cuidadosa o processo de seleção natural aplicado de forma geral a todas as espécies de seres vivos, nenhuma alusão à seleção natural aplicado à humanidade; é apenas em "The Descent of Man” (1871) que Darwin trata o ser humano como resultado do processo evolutivo a que estão submetidas todas as espécies de seres vivos e desenvolve seus argumentos acerca do "parentesco" entre as espécies do mundo animal e o ser humano. Mas, alerta Darwin nesta mesma obra, há uma diferença crucial entre seres humanos e outros animais: apenas os primeiros são capazes de agir moralmente.

As raízes da moralidade humana eram atribuídas pelo cientista aos instintos sociais, estes capazes de promover a ação cooperativa (e não a competição aclamada pelos darwinistas sociais, como logo veremos em Spencer) em nome do "bem comum". Darwin levou às últimas consequências a premissa aristotélica de que o homem é por natureza um ser moral e tomou a capacidade de agir moralmente como um avanço singular da seleção natural na conquista da sobrevivência física. Ainda que a incursão pelas ideias de Darwin seja muito curta é possível perceber que a seleção natural não era balizada por um processo de competição intra e inter-espécies, a "luta pela sobrevivência" aclamada pelos social darwinistas; tão pouco eram as propostas de Darwin, expressas tanto em "A Origem das Espécies" e "The Descent of Man", a defesa do status quo do mundo ocidental em meados do século XIX.

A aplicação das propostas de Darwin à sociedade ocidental de fins do século XIX fora feito por outra pessoa, o inglês Herbert Spencer (1820-1903). Spencer, embora não tenha gozado de muita fama em sua terra natal, tem suas ideias aclamadas nos EUA como cruciais na formação do pensamento sociológico norte-americano.

Foi Spencer quem cunhou o conceito de "sobrevivência do mais apto" que Darwin prontamente aceitou. Spencer e sua filosofia, como argumenta Hofstadter (1965), são produtos da sociedade inglesa de meados do século XIX em que a ciência natural e o industrialismo eram as grandes forças. Assim, o conceito de conservação de energia (isto é, matéria e energia não se dispersam, mas transformam-se) associado ao conceito darwiniano de seleção natural dava forma ao anseio de Spencer de construir um conhecimento definitivo sobre a humanidade no qual física e biologia seriam os aportes principais. 
A lei da conservação de energia, ou a "persistência da força" é o ponto de partida da leitura que Spencer faz da obra de Charles Darwin. Segundo esse princípio, o processo vital é essencialmente evolutivo, ou seja, os organismos caminham, na escala evolutiva, de massas homogêneas e incoerentes à complexidade dos organismos dos grandes animais e dos seres humanos. Por esse princípio, Spencer inferiu que tudo que é homogêneo é instável por natureza já que seu destino provável, dado pela lei da conservação de energia, é a diferenciação progressiva. Assim, organismos homogêneos (os protozoários como exemplos) desenvolver-se-ão inevitavelmente em organismos heterogêneos e complexos; o resultado final desse processo é o estado de equilíbrio, estágio inevitável já que o processo evolucionário não caminha indefinidamente rumo a uma diferenciação infinita.

Era esse esquema biológico da evolução das espécies que Spencer aplicou às sociedades humanas, isto é, os princípios de estruturação e de mudança social devem obedecer àqueles que governam o universo, ou para utilizar uma linguagem cara ao darwinismo social, todos os seres vivos, inclusive o homem, estão submetidos aos mesmos processos evolutivos.

Mas não foi só em Darwin que Spencer inspirou-se: há um outro nome, devemos lembrar, que conformou as ideias sobre natureza e sociedade no final do século XIX: referimo-nos a Jean Baptiste de Lamarck. De uma forma muito sutil, a premissa lamarckiana (elaborada em meados do século XVIII) de que os caracteres adquiridos pela experiência e pelo hábito são transmissíveis a outras gerações, embora estivesse em flagrante discordância com a proposta darwiniana, compõe de forma clara as formulações de Spencer e seus contemporâneos. Stocking (1982) aponta argutamente a presença das premissas lamarckianas em seu breve estudo sobre o lamarckismo (ou sua re-leitura, o neolamarckismo) no pensamento social americano do final do século XIX e início do século XX.

Spencer defendeu ardorosamente a herança dos caracteres adquiridos frente às pesquisas levadas a cabo pelo biólogo August Weismann (1834-1914) sobre a impossibilidade de células somáticas atuarem como veículos da hereditariedade ${ }^{2}$. Para Spencer e tantos outros pensadores que abraçaram o evolucionismo social, a evolução humana procedia por uma única sequência cumulativa de estágios culturais e sociais; neste esquema, a herança de caracteres adquiridos assumia pelo menos dois papéis importantes: aquele que explicava de

${ }^{2}$ Pelas pesquisas desenvolvidas por Weismann, fica provado que a hereditariedade apenas se dá nas células germinativas - os gametas. Sendo assim, são as células germinativas que produzem células somáticas (entendidas como as demais células que compõem o ser vivo) e 
forma irrepreensível as origens das diferenças raciais (as raças tem origens diversas e são irredutíveis umas às outras) e outro que promovia uma ligação direta entre progresso social e evolução orgânica (progresso material era equivalente à superioridade biológica de determinadas raças).

É claro o diálogo da ecologia humana da Escola de Chicago com as propostas do darwinismo social- os conceitos de "competição", "sobrevivência do mais apto" e "distribuição geográfica", bases da ecologia humana, são provas desse frutuoso intercâmbio como veremos de forma inequívoca quando tratarmos com maior cuidado do trabalho de Robert Park. Neste momento, é importante notar que não é possível traçar, na conformação de propostas teóricas e metodológicas, linhas inequívocas e fronteiras marcadas entre matrizes e filiações teóricas mesmo que divergentes como lamarckismo e darwinismo- no panorama intelectual desse período, é preciso evitar avaliações taxativas sobre tal ou qual filiação teórica sob pena de injustiça no tratamento da obra desses pensadores, e é por esta razão que a metáfora da colcha de retalhos é tão produtiva: são elementos incombináveis que somados dão materialidade e sentido a um corpo teórico original. Se voltarmos nossa atenção para a confecção dessa colcha de retalhos é possível distinguir uma outra peça importante nesse quebra-cabeça: o pragmatismo social.

\section{Pragmatismo social}

Para entender o pragmatismo social devemos ter em mente sua posição crítica diante da voga social darwinista (segundo uma leitura spenceriana, principalmente) que tão bem caracterizou o pensamento social norte-americano em seu advento; sugiro que o pragmatismo, em muitos pontos, distancia-se do darwinismo social especialmente no que toca à relação natureza e sociedade. Embora, ambos compartilhem da ambiência intelectual de predominância das ciências naturais como gabarito da produção científica, há, do lado dos pragmatistas, uma postura crítica diante dos postulados do darwinismo social no que concerne à relação sociedade e natureza, isto é, do ponto de vista pragmático, a natureza não reina absoluta no mundo humano- há um grau de liberdade de ação e de escolha da humanidade diante da natureza. Se da ótica darwinista, a natureza é estrutura que esmaga o humano, do ponto de vista pragmático, o agente é capaz de dobrar a natureza e submetê-la a seus desígnios.

nada que afete essas células altera os elementos a serem transmitidos hereditariamente 
Primeiro, reconheçamos os grandes nomes do que se convencionou chamar de pragmatismo: desde o final do século XIX, William James (1842-1910), John Dewey (18591952), Charles Peirce (1839-1914) e George Herbert Mead (1863-1931) tem dado formato a teoria. A despeito da polêmica em torno do nominalismo ou realismo (Hofstadter, 1965) dessa proposta, é possível propor que o pragmatismo coloca o humano no centro do pensamento social, ou seja, a maleabilidade e perfectibilidade da consciência humana têm como resultado possível um processo de mudança social. Para um mundo convencido da sobrevivência dos mais aptos e do fenecimento dos ditos mais fracos, o pragmatismo ilumina as possibilidades de reformas e mudanças sociais.

O pragmatismo, embora compartilhe os supostos lamarckistas do social darwinismo (a herança de caracteres adquiridos para sermos exatos), ele o faz de modo muito peculiar: a ênfase está na herança da capacidade de mudança e de adaptação do homem (e não da sobrevivência do mais apto e fenecimento do mais fraco) quando diante de constrangimentos naturais e sociais. Assim como Spencer sustentou o determinismo e o controle do homem pela natureza, os pragmatistas sustentaram a liberdade e o controle da natureza pelo homem como característica per se da humanidade.

Pode-se sugerir, de forma ainda que simplista, que a contribuição mais importante do pragmatismo social para o pensamento sociológico americano foi a promoção de uma crença na efetividade das ideias e na possibilidade de transformação no mundo social, uma posição crucial para uma teoria consistente de reforma social tão bem desenvolvida em princípios do século XX por pesquisadores ligados sociologia da Universidade de Chicago. Embora compartilhasse as premissas biológicas do comportamento humano com o darwinismo social, a ecologia humana da Escola de Chicago apostava na capacidade de subversão da ordem natural das coisas em nome de um valor maior, a dignidade humana.

Tendo em mente esse breve panorama intelectual acerca do tema natureza e sociedade no final do século XIX e início do século XX nos EUA, olhemos para o objeto central desse trabalho, as distâncias e proximidades entre Robert Park e George Simmel no que toca os temas sociedade/natureza e, principalmente, indivíduo e sociedade.

\section{Park versus Simmel}

Um outro elemento dessa bricolagem que é o pensamento da ecologia humana da Escola de Chicago é o pensamento de Georg Simmel (1858-1918). O que gostaria de trazer à 
tona não é tanto o que Simmel disse, mas principalmente como foi lido e tomado pelos pensadores americanos. No que toca à relação natureza e sociedade, podemos sugerir que à dicotomia, nos supostos darwinistas, contrapõe-se uma relação dialética entre sociedade e natureza que é apenas esboçada nas propostas pragmatistas e amplamente desenvolvida no pensamento de Simmel.

Como pretendo demonstrar ao longo da exposição, o darwinismo social está à frente dos diálogos com Simmel na confecção da ecologia humana; a ecologia humana e o pensamento simmeliano compartilham conceitos (como de assimilação, conflito, distância social, estrangeiro e tantos outros) mas o faz de forma muito superficial, ou seja, embora partilhem do mesmo nome, os supostos e as ideias são muito distintas em cada grupo de propostas. Sugiro que os conceitos simmelianos, presentes de forma clara na ecologia humana de Park, são lidos essencialmente via ciências naturais, ou seja, a bricolagem de elementos na conformação da grande colcha de retalhos que é a ecologia humana segue uma lógica muito específica, aquela das ciências naturais que tão bem caracterizou a sociologia americana em seu advento. A ecologia humana dos americanos é, portanto, evolucionista e não sociológica, e esse é o ponto que pretendo demonstrar aqui; nesse sentido, a presença simmeliana, no pensamento de Robert E. Park, é traduzida em ausência ao apontarmos que é a ótica evolucionista a pedra de toque da ecologia de Robert Park.

Para ter clara essa proposição, aproximemo-nos do o pensamento de Simmel a partir de suas distâncias com relação a Robert E. Park. Elencamos duas naturezas de diferenças, as epistemológicas e as teóricas.

Quanto às epistemológicas, Robert E. Park (1864-1944) divide a análise científica em dois níveis, o ecológico e o sociológico. No primeiro nível, a Ecologia Humana está encarregada do estudo do nível biótico da vida, ou seja, o estudo das condições de existência de uma comunidade. Como pressuposto metodológico da sociologia, a ecologia humana toma como objetivo o entendimento da base biótica da vida social.

O ponto de partida da Ecologia Humana é o mesmo que o da ecologia vegetal e a animal: o fato básico para estas ciências é a existência, tanto entre seres humanos como entre plantas e animais, de uma competição constante por um lugar no espaço. No decorrer deste processo de assentamento e acomodação no espaço desenvolve-se, pouco a pouco, certa ordenação da configuração vegetal, animal ou humana, uma teia de relações sociais, que é antes biótica que social; por meio desta "teia da vida" indivíduos, grupos de indivíduos e instituições sociais tornam-se interdependentes por meio da especialização de cada unidade 
em uma determinada função na "economia biológica" do sistema.

A proposição básica que permeia as reflexões de Robert E. Park é que no nível ecológico da vida humana, atua um processo espontâneo, não intencional e contínuo - a competição - que leva os seres humanos a desenvolveram inconscientemente uma organização biótica interdependente e a se distribuírem ordenadamente no espaço.

Assim, a ecologia humana estuda o processo de competição e as relações que dele provenham tal como essas se revelam por índices físicos, principalmente os de espaço. A ecologia humana, em poucas palavras, se interessa pelas relações sociais traduzidas em relações espaciais ${ }^{3}$. E, uma vez que estas relações sempre se encontram na superfície da terra, pode-se com razão concebê-las como tendo aspectos espaciais, sendo assim suscetíveis de serem representadas em mapas; em outras palavras, se a vida social se processa a partir de um arcabouço ecológico, pode-se com razão esperar que se desenvolverá certa ligação entre a organização social, de um lado, e a organização ecológica, de outro, ligação essa traduzível em mapas da vida social. Entretanto, as inter-relações entres seres humanos e desses com seu habitat são comparáveis, porém não idênticas, às inter-relações de outras formas de vida animada. O homem, como argumenta Robert Park (1948), por meio de invenções e recursos técnicos aumentou enormemente sua capacidade de reagir aos desafios da natureza e refazer o seu habitat. O homem guarda sua peculiaridade com relação às outras formas de vida animada justamente porque erigiu, sobre a base biótica da comunidade, uma estrutura institucional enraizada no costume e na tradição, a sociedade (PARK, 1948: p.33).

Assim, a sociedade humana é organizada, no pensamento de Park, em dois níveis, o biótico e o cultural. Há uma sociedade simbiótica baseada na competição e uma sociedade cultural baseada na comunicação e no consenso. As duas sociedades, argumenta Park (1948), são simplesmente aspectos diferentes de uma sociedade- a superestrutura cultural repousa sobre a base da subestrutura simbiótica e as energias que se manifestam no nível biótico em movimentos e ações revelam-se no nível social superior em formas mais sutis e sublimadas.

À ecologia cabe o estudo e a explicação deste nível da sociedade comum a todas as formas de vida animada, o biótico. À sociologia, cabe o estudo e compreensão da "expectativa normal do gênero humano, dos mores, aquilo que os homens, numa situação definida, vieram

${ }^{3}$ Robert Redfield, pupilo de Park, oferece um exemplo clássico da tradução de relações sociais em relações espaciais: em seu "Folk Cultures of the Yucatán"(1948), utiliza uma ferramenta teórico-metodológica, o contínuo folk-urban, segundo o qual o espaço é um índice do grau de modernização das comunidades ocupadas: quanto mais próximas do litoral, mais modernas; quanto mais distantes do litoral, mais tradicionais. 
a esperar" (PARK, 1948: p.35). A Sociologia e as outras ciências sociais tratam, portanto, do estudo da "vida", esta entendida como manifestação da cultura humana e a ecologia humana, por seu turno, trata do substrato, do "palco" no qual se processa a vida humana.

Simmel coloca-se como antípoda a essa argumentação naturalista. Georg Simmel, como sugere Coser (1965), encontra-se entre duas tradições filosóficas, o evolucionismo de Spencer e Comte e o nominalismo da Geisteswissenschaft alemã. Do ponto de vista evolucionista, processos sociais são tidos como equivalentes de processos biológicos pois sociedade e natureza são, poderíamos sugerir, "moldados do mesmo barro". Uma proposta muito distinta foi construída pela filosofia idealista alemã. A tradição alemã tomava o Naturwissenschaft e o Geisteswissenschaft como qualitativamente distintos: leis naturais não tinham lugar no estudo da cultura humana, locus per se da liberdade; nesse sentido, o afã da Geisteswissenschaft era coletar e descrever a particularidade da história humana numa tarefa qualitativamente distinta daquela a que estava dedicada a Naturwissenschaft a qual cumpria descrever e entender a ordem da natureza.

Simmel, opondo-se a essas duas posturas tão claramente distinguidas no pensamento alemão do século XIX, toma como tarefa da sociologia o conhecimento de leis típicas; se aceita, por um lado, o postulado do idealismo alemão de que não existe sociedade mas indivíduos, de outro lado, toma o caráter generalizador, inspirado nas ciências naturais, para propor as formas sociais como as unidades da análise sociológica. Simmel não tomava a sociedade à moda evolucionista, como um organismo; tão pouco a tem como a soma das existências individuais, algo que não possui existência real separada dessas existências particulares, à maneira dos idealistas alemães. A partir de uma bricolagem de elementos muito distintos (a metáfora da colcha de retalhos encaixa-se muito bem aqui), sociedade, no pensamento simmeliano, é tomada como uma intricada rede de múltiplas relações em constantes interações estabelecidas entre indivíduos e destes com o mundo material. Sociedade, se possível delimitar, é um nome dado a indivíduos e coisas conectados por processos de interação social. O objeto da sociologia não é, portanto, "sociedade" ou “indivíduos", mas essas formas de interação social.

Tal como tipos ideais weberianos (sugerimos uma aproximação com fins didáticos e não a equivalência entre os conceitos), as formas sociais são abstrações ou modelos retirados da realidade social que correspondem a padrões de interação sociais. Formas sociais são, portanto, superiores às existências individuais e não estão submetidas às vontades humanas; essa superioridade da forma sobre o indivíduo não resulta de uma força supraindividual, (tal 
como delineada por propostas à moda estruturalista- Durkheim e Robert Park como exemplos), mas sim da natureza da interação social: se operativos em todos os membros do grupo, as reciprocidades não podem ser subvertidas segundo vontades individuais.

Do ponto de vista metodológico, não é difícil perceber as distâncias entre Park e Simmel; embora o último tenha sido inspiração do primeiro especialmente no que toca à convivência de níveis comunitários e societários de interação social, fica claro que a construção da ecologia humana levou em consideração uma lógica firmemente naturalista que tomava a sociedade como submetida à constrangimentos naturais, nada mais distante da ótica simmeliana que tomava a sociedade como fluxo de relações propriamente sociais. Pode-se sugerir uma analogia interessante: à natureza de Park corresponde a estrutura social de Durkheim com todo seu peso e inexorabilidade sobre os ombros do homens; a natureza de Simmel, de outro modo, é tomada como artefato humano, paisagem na qual o olhar humano comanda sua elaboração, proposição que logo mais desenvolverei.

Do ponto de vista teórico, é possível isolar, pelo menos, quatro proposições no que toca às diferenças entre os dois autores: as noções de "estrangeiro", conflito social, distância social e, finalmente, os sentidos de natureza em ambos os autores.

O primeiro ponto: o "estrangeiro". O estrangeiro é para Simmel, o tipo social que condensa a dialética entre proximidade e distância que tão bem qualifica as relações sociais na metrópole de inícios do século XX; a figura do estrangeiro deixa clara as dificuldades do viver em grupo numa sociedade em constante transformação como a grande cidade. Como alguém que é parte do grupo, mas ao mesmo tempo está fora dele, o estrangeiro simboliza uma forma específica de interação muito distante das relações comunitárias em que a distância social entre seus membros é mínima; o estrangeiro traz uma forma especificamente metropolitana de relacionar-se, pois é a relação dialética entre proximidade e distância que informa o lugar a ser ocupado, ou seja, os elementos que repelem e aumentam a distância produzem um modelo positivo e consistente de interação.

O estrangeiro recebe outro nome no pensamento de Robert Park, "marginal man". O novo nome guarda grandes diferenças com relação a seu ancestral: o "marginal man" de Park guarda um sentido negativo da distância social; o estrangeiro é, no esquema de Park, o que está nas margens, o não assimilado, o que está de fora e permanecerá de fora das interações sociais. Ao pensar as experiências das minorias étnicas em zonas de contato cultural em grandes cidades norte-americanas, Park toma o estrangeiro como um elemento marginal à sociedade, um híbrido cultural e racial que participa de duas ou mais configurações culturais, 
mas não é parte de nenhuma delas.

Esse sentido negativo do "estrangeiro", presente no pensamento de Robert Park, guarda uma relação com uma leitura muito peculiar de outro conceito caro ao pensamento simmeliano: conflito social. Para Simmel, cada tendência na interação social é, de algum modo, contrabalançada por uma tendência oposta: Simmel concebe a sociedade como composta de um dualismo fundamental dado pela ambivalência das disposições instintivas do homem, forças discordantes que se harmonizam e dão uma forma peculiar a sociedade. Dentre essas disposições ambivalentes que se equilibram, pode-se citar a conformidade versus a individuação, o constrangimento versus a liberdade, o público versus o privado. É possível perceber que Simmel atribui um sentido positivo ao conflito- como antagonismo rotinizado, o conflito dá um sentido positivo à interação e é, portanto, uma forma de associação social.

No pensamento de Robert Park, conflito toma um sentido oposto: é uma fonte de perturbação, um sinal de que mudanças são necessárias; como um momento do processo de mudança social, o conflito contribui com uma fissura na ordem moral que deve e será sanada por meio de processos de acomodação e assimilação; embora necessário, o conflito é um momento de interrupção da ordem moral, nada mais distante do caráter associativo do conflito na acepção simmeliana.

Um outro conceito que dá conta das diferenças entre os dois autores é o de "distância social“; no pensamento de Simmel, distância social surge como conceito correlato de "estrangeiro"; tal como uma metáfora que denota a posição peculiar do estrangeiro na sociedade, "distância social" geometriza a dialética entre proximidade e distância que caracteriza esse tipo social. Nas formulações de Robert Park, este conceito tem centralidade; "distância social" tornou-se um conceito importantíssimo na sociologia americana em meados da década de 1920 devido ao grande afluxo de migrantes e imigrantes para as grandes cidades norte-americanas. Como uma forma de medir a possibilidade e a intensidade de conflitos sociais entre grupos cultural e etnicamente tão distintos que passaram a compor as grandes cidades americanas, o conceito de distância social, metáfora em Simmel, é quantificado e traduzido em um índice concreto das relações sociais, uma medida do equilíbrio social nas propostas de Robert Park. Muito longe do humanismo de Simmel, esse índice é, sem dúvida, um indício do substrato naturalista da ecologia humana pensada por Park e seus discípulos.

É possível perceber que as proposições de Georg Simmel são lidas pelos americanos de uma forma um tanto quanto naturalista: as lentes do evolucionismo social e a ânsia por esquadrinhar a realidade e prescrever remédios ao conflito social são as pedras de toque da 
sociologia pensada por Park. As distâncias com relação ao conceito de natureza entre os dois autores é só mais um elemento que confirma esta tese.

Como já explicitado anteriormente, não há em Simmel a distinção entre dois níveis analíticos de análise tal como desenhado por Park; esta característica pode ser explicada pela dicotomia que representa as relações entre natureza e sociedade neste último autor. Ao aceitar o ponto de vista evolucionista, natureza e sociedade são tomadas como elementos de uma relação dicotômica que nunca se resolve, ou seja, dominante e dominado, a sociedade se curva diante da força da natureza. Como elemento externo ao comportamento humano, a natureza opera como "meio", elemento determinante de ações e relações sociais tal como H. Taine (1828-1893) e T. Buckle (1821-1862) outrora profetizaram. Como um prisioneiro em sua própria casa, à sociedade resta curvar-se à força da natureza.

De um ponto de vista oposto pensa Simmel; corroborando as propostas da Geisteswissenschaft, a natureza não é elemento determinante na conformação de comportamentos sociais. Como propõe Gross (2001), Simmel elabora, a partir do conceito de interação social, um meio termo entre natureza como "meio" (a sociedade subjugada à natureza) e "paisagem" (a natureza subjugada à sociedade). Vejamos como esse ponto de vista tão peculiar toma forma no pensamento de Simmel.

Nos trabalhos de Simmel, é possível identificar dois textos que nos esclarecem este movimento entre dois sentidos de natureza. O primeiro texto "A filosofia da paisagem" (1913) traz a natureza reduzida a um recorte humano do mundo natural, "o ilimitado nos seus limites sem falhas", a "paisagem". Resultado do processo de recorte e abstração da realidade social e material, a paisagem é tomada como "forma social". Lembremo-nos de que a sociologia formal proposta por Simmel é um expediente criado para contornar a multiplicidade da realidade humana na análise sociológica, isto é, diante da riqueza da Vida, a razão constrói camadas dotadas de autonomia e lógica próprias, numa acepção muito próxima das esferas autônomas de ação social pensadas por Max Weber. É sob esse ponto de vista que é possível pensar em uma forma completamente humanizada e depurada da natureza como a paisagem.

A natureza tomada como "o nexo infindo das coisas, a ininterrupta parturição e aniquilação das formas, a unidade ondeante do acontecer, que se expressa na continuidade da existência espacial e temporal" (SIMMEL, 2009: 05), é como que contida na moldura da paisagem. Tal como nos ensina a arte pictórica, é o olhar e o sentir (stimmung) humanos que promovem esse recorte da natureza e a provê de uma existência e lógicas próprias separadas 
do mundo da Vida, a existência puramente artística. É claro que essa percepção do mundo natural desenvolve-se num período específico da lenta construção do modo de vida moderno. Como resultado do processo lento de civilização, ou seja, de domínio das forças naturais (externas e internas ao homem) pela cultura, a paisagem é a natureza "culturalizada" (GROSS, 2001), ponto alto do trabalho e da imaginação humanas concretizadas numa moldura que limita e organiza o caos da natureza.

Simmel, contudo, não cessa neste ponto suas reflexões acerca da relação natureza e sociedade; não somente é a natureza traduzida em cultura, mas também a cultura traduzida em natureza, o que nos leva ao segundo sentido de natureza trabalhado por Simmel: a "ruína". Outra forma social, a ruína nos conta, tal como a paisagem, sobre um pequeno mas válido excerto do mundo da vida que é muito valioso na compreensão das relações entre sociedade e natureza. A ruína é a cultura invadida e tomada pela natureza. O ponto crucial de seu argumento é que um produto do trabalho humano, a construção, toma um desenvolvimento independente do planejamento humano: o objeto cultural outrora forjado pela perícia humana é "naturalizado", é tornado parte da natureza. Gross utiliza o conceito de "cultivation" (que poderia ser traduzido como "cultivo") para expressar a invenção de uma "nova natureza" que guarda seu caráter não-planejado e independente do envolvimento humano. Neste sentido, natureza também é tomada como ator social: "Nature has transformed the work of art into material for her own expression (Formung), as she had previously served as material for art" (GROSS,2001: p. 400).

Percebe-se que natureza toma no pensamento de Simmel um sentido muito peculiar diante das soluções evolucionistas (a cultura reduzida à natureza) e culturalistas (a natureza reduzida à cultura) e isso se dá essencialmente pela ideia de sociedade e sociologia que Simmel constrói. São as redes de interações recíprocas entre indivíduos e entre estes e o mundo material os objetos de análise da sociologia, como já adiantamos em parágrafo acima. A natureza, portanto, é tornada objeto de estudo da sociologia a partir de um ponto de vista humanista, como elemento dessa rica rede de interações recíprocas entre homens e desses com a realidade.

Distanciando-se da proposta de outro grande nome da sociologia clássica, E. Durkheim, Simmel não incorpora a natureza à sociedade; tampouco dilui a sociedade no fluxo incessante da natureza, pelo contrário: Simmel dá voz a ambos os lados, o humano e o natural, na compreensão da relação sociedade e natureza no mundo moderno promovendo um equilíbrio entre culturalismo e naturalismo. Seu ponto de vista teórico enfatiza de que modo 
atividades humanas modificam a natureza e, de outro lado, quais as "respostas" da natureza a essas ações que engendram uma forma específica de relação social: a dicotomia da relação sociedade/natureza expressa no determinismo do século XIX é diluída em prol de uma relação dialética sem síntese.

Seu ponto de vista acerca da relação natureza e sociedade pode ser ampliado de modo a abarcar a relação entre sociedade e indivíduo tal como construído em seu pensamento: longe de privilegiar um ou outro, Simmel atenta para os jogos de relações entre ambos de modo a descortinar possibilidades de ações e posições. Do mesmo modo, é possível sugerir que o ponto de vista de Robert Park acerca da relação sociedade e natureza tem sua equivalência na leitura que o autor tem da relação entre sociedade e indivíduo: os pares são tomados como dicotomias cujos elementos se opõem de forma essencial de modo que é possível pensar na predominância de um sobre o outro, natureza sobrepondo-se à sociedade, sociedade sobrepondo-se às forças individuais.

Para esclarecer essa última proposição, olhemos para o "estrangeiro" de Simmel e o "marginal man" de Robert Park. No primeiro caso, o "estrangeiro" representa o modelo de relações sociais na sociedade moderna: como uma síntese sui generis entre distância e proximidade, o "estrangeiro" enquanto forma social (que, estejamos atentos, trata-se de uma abordagem de "meio-caminho" entre análises estruturalistas e aquelas que privilegiam o indivíduo) apresenta o "lugar" do indivíduo nas sociedades modernas. Robert Park, por sua vez, parte de um ponto de vista oposto: seu tipo social, o "marginal man", informa-nos acerca da ausência de um "lugar" para o indivíduo em uma ordem social num momento de grandes transformações sociais; parece não existir um lugar para quem não está "nem lá e nem cá" na sociedade americana do começo do século XX, de modo que o que parece contar para a sociologia de Park é o indivíduo quando imerso em relações sociais típicas da comunidade.

É possível citar um outro exemplo: a mera presença do conceito de paisagem na sociologia simmeliana, de um lado, e a noção de natureza como "meio" tão característica no pensamento de Park nos contam do modus operandi, poderíamos assim sugerir, do pensamento de cada autor: como vimos há pouco, "paisagem" implica a presença do olhar humano e "meio" sugere uma relação determinista entre natureza e sociedade. Os exemplos poderiam ser multiplicados de modo a ser possível identificar os diferentes pontos de vistas de cada autor acerca da relação indivíduo e sociedade: Robert Park, numa posição mais próxima de um estruturalismo e George Simmel numa posição mais matizada que prima pelo "movimento" entre indivíduo e sociedade. 


\section{Comentários Finais}

Há, é certo, inúmeros outros caminhos para se perscrutar as distâncias e as proximidades entre o pensamento de Robert Park e Georg Simmel e há ainda tantos outros modos de acessar o grande tema indivíduo e sociedade na obra desses dois grandes autores do pensamento sociológico. Nesse trabalho, como ficou claro, privilegiei um certo ponto de vista, as relações entre sociedade e natureza e assim fiz pelos interesses intelectuais que tenho acerca de um novo (não tão novo assim) ramo dos estudos sociológicos, a sociologia ambiental. O esforço primevo deste trabalho era iluminar um tema que, classicamente, não recebeu tanta atenção da sociologia, a relação sociedade e natureza, mas que, atualmente, conforma-se em um tema riquíssimo que se oferece como uma chave compreensiva valiosa para temas clássicos do pensamento sociológico, como a relação indivíduo e sociedade por exemplo.

Com esse trabalho, espero ter, pelo menos, apontado o quão frutífero e original pode ser a sociologia ambiental nas leituras dos clássicos do pensamento sociológico: 'natureza', embora tenha sido deixada um pouco de lado na história da disciplina, tem uma presença profunda que remete a temas clássicos da sociologia. Para além de apontar essa possibilidade teórica, gostaria também de apontar para a necessidade, diante da novidade (quiçá gravidade) das relações sociedade e natureza na sociedade contemporânea, de incorporar tal tema às reflexões sociológicas - o primeiro passo para que a natureza entre "pela porta da frente" da disciplina é tomá-la nos clássicos. Eis uma pequenina contribuição que tenho tentado explorar em trabalhos de maior amplitude.

\section{Referências Bibliográficas}

COSER, LEWIS A. (ed.). Georg Simmel. Englewood Cliffs, New Jersey: Prentice-Hall Inc, 1965.

COULON, Alain. A Escola de Chicago. Campinas,SP: Papirus,1995.

DEGLER, Carl N. In search of Human Nature. The decline and the revival of Darwinism in the American Social Thought. New York: Oxford University Press, 1991.

EUFRÁSIO, MARIO. A. Estrutura Urbana e Ecologia Humana: A escola sociológica de Chicago (1915-1940). Editoria 34. São Paulo, 1999. 
FARIS, Robert. Chicago Sociology 1920-1932. Chicago: The Chicago University Press, 1967.

GROSS, MATTHIAS. "Unexpected interactions: Georg Simmel and the observation of nature”. In: Journal of Classic Sociology, vol.1, n.3, p. 395-414, 2001.

HOFSTADTER, Richard. Social Darwinism in the american thought. Boston: The Beacon Press, 1965.

OLIVEIRA, LÚCIA.L. "Donald Pierson e a Sociologia no Brasil". In: BIB, Rio de Janeiro, n.23,p. 35-48, $1^{\circ}$.sem. de 1987.

PARK, Robert E.“Ecologia Humana”. In: Pierson, Donald (org). Estudos de Ecologia Humana.São Paulo, Livraria Martins Editora, p. 21-36, 1948 (Tomo I de Leituras de Sociologia e Antropologia Social).

PIERSON, Donald. "Ecologia Humana". In: Sociologia: revista dedicada à teoria e pesquisa nas Ciências Sociais, v. 9, n. 2, p. 153-163, 1947.

“Exame crítico da Ecologia Humana". In: Sociologia: revista dedicada à teoria e pesquisa nas Ciências Sociais, v. 10, n. 4, p. 227-241, 1948a.

. "Introdução". PIERSON, DONALD (org). Elementos de Ecologia Humana. São Paulo: Livravia Martins Editora, p. 07-17, 1948b (Tomo I de Leituras de Sociologia e Antropologia Social).

SIMMEL, G. “A Ruína”. In: SOUZA, Jessé e ÖELZE, Berthold. Simmel e a modernidade. Brasília: UnB., p.137-144, 1998.

SIMMEL, G. Filosofia da paisagem. Covilhã: Universidade da Beira Interior, 2009. ( $1^{\mathrm{a}}$. Edição: 1913). Disponível em http://www.lusosofia.net/

SIMMEL, G. "O estrangeiro". In: MORAES FILHO, EVARISTO. George Simmel: sociologia. São Paulo: Ed. Ática, p. 182-188, 1983.

SIMMEL, G. "A metrópole a vida mental". In: O fenômeno urbano. Rio de Janeiro: Ed. Zahar, p.13-28, 1967.

STOCKING, GEORGE W. Race, Culture and evolution: essays in the history of anthropology. Chicago/London: The University of Chicago Press, 1982. 